\title{
Studies of natural and accelerated carbonation in metakaolin-based geopolymer
}

\author{
POUHET Raphaëlle ${ }^{1, a^{*}, \text { CYR Martin }}{ }^{2, b}$ \\ 1,2, Université de Toulouse, UPS, INSA, Laboratoire Matériaux et Durabilité des Constructions, 135, \\ Avenue de Rangueil, F-31077 TOULOUSE Cedex 4, France \\ a pouhet@insa-toulouse.fr, ${ }^{b}$ martin.cyr@insa-toulouse.fr
}

Keywords: Geopolymer, carbonation, Metakaolin, Efflorescence, Durability.

\begin{abstract}
The carbonation of Portland-cement-based materials involves the reaction between atmospheric $\mathrm{CO}_{2}$ and calcium ions in the pore solution. The formation of calcium carbonate is responsible for a decrease in the $\mathrm{pH}$ of the pore solution from 12.5 to 9 , thus leading to the depassivation of steel reinforcements and their possible corrosion, and can also lead to efflorescence (white crystals formed on the surface). In metakaolin-based geopolymer activated by sodium silicate, in which calcium is almost non-existent, the presence of $\mathrm{CO}_{2}$ will lead to the formation of sodium carbonates. Since geopolymer can be carbonated, the risk of corrosion or efflorescence needs to be assessed.

A pH study of the geopolymer pore solution showed a very fast decrease compared to OPC, with almost total carbonation after only 14 days. In natural atmospheric $\mathrm{CO}_{2}$ conditions, it was found that the formation of sodium carbonate did not lead to a decrease of the $\mathrm{pH}$ to below a value around 9, thus limiting the risk of corrosion by depassivation of reinforcement, but the large amount of carbonate suggested a significant risk of efflorescence. A study of accelerated carbonation performed under an atmosphere of $50 \% \mathrm{CO}_{2}$ highlighted the formation of sodium bicarbonate resulting in a lower $\mathrm{pH}$ of the pore solution and a much larger amount of product formed. Finally the study of efflorescence carried out by semi-immersion tests in natural or accelerated conditions confirmed the different nature of the crystals formed (sodium carbonate or bicarbonate) but showed no significant impact on the amount of carbonated products. This study thus demonstrates that the accelerated carbonation test had very limited usefulness, given the rapidity of the natural reaction. Furthermore, it was found that this test did not reproduce reality as it led to different reaction products.
\end{abstract}

\section{Introduction}

The carbonation of Portland cement pastes is well known as a slow reaction leading to the formation of insoluble calcium carbonate deeper and deeper in the structure. The consequence of this carbonation is a gradual decrease in the $\mathrm{pH}$ of the pore solution. The $\mathrm{pH}$ can reach a value lower than 9, which is the limit value for the depassivation of steel in the concrete, and thus cause corrosion by carbonation. In addition, the dissolution of $\mathrm{CO}_{2}$ in the pore solution could lead to the carbonation of the alkalis present in small quantities in the cement and cause efflorescence (white crystals appearing on the surface). The study of carbonation is usually performed in accelerated conditions (more concentrated $\mathrm{CO}_{2}$ atmosphere) and the carbonation front is followed by means of a coloured indicator (phenolphthalein). In geopolymer based on metakaolin or fly ash with very low calcium content, dissolved $\mathrm{CO}_{2}$ reacts with the abundant alkalis in the pore solution to form alkalicarbonates. For geopolymer activated by sodium silicate, it has been shown $[1,2,3,4]$ that sodium carbonates are formed but the high solubility of these carbonates and their $\mathrm{pH}$ greater than 10 may make the use of a phenolphthalein test unsuitable. In addition, the use of accelerated tests has been questioned as not being representative of the reaction taking place in standard conditions, and resulting in the formation of sodium bicarbonate [4]. 
This study aims to evaluate the behaviour of the pore solution of metakaolin-based geopolymer pastes activated by sodium silicate in the presence of $\mathrm{CO}_{2}$ (natural and accelerated conditions) to identify the product of the reaction, and evaluate the rate of carbonation and the resulting risk of this reaction, using infrared spectroscopy and chemical titrations.

\section{Materials and methods}

The raw material used in this study was a metakaolin made with a "flash" calcination process [5]. Flash calcination refers to the combustion process (temperature around $700^{\circ} \mathrm{C}$ ) where the particles of kaolinite are transformed into metakaolin by passing near a flame for a few tenths of a second. This process is faster and consumes less energy than traditional methods (e.g. rotary kiln). Due to the low purity of the deposit, this metakaolin contained about $50 \%$ of impurities, mainly quartz (44\%). The quartz percentage was not taken into account as silica available for the formulation of the geopolymer. The activating solution was an industrial waterglass solution (Bétol 47T, Woellner) containing $17 \% \mathrm{Na}_{2} \mathrm{O}$ by mass and having an $\mathrm{SiO}_{2} / \mathrm{Na}_{2} \mathrm{O}$ ratio of 1.6. All the pastes were prepared by mixing the components into the following mass percentage: $52 \% \mathrm{MK}, 41.5 \%$ alkali silicate, and $6.5 \%$ water, until a homogeneous mixture was obtained. Thus the geopolymer paste had the following molar ratios: $\mathrm{SiO}_{2} / \mathrm{Al}_{2} \mathrm{O}_{3}=3.6, \mathrm{Na}_{2} \mathrm{O} / \mathrm{Al}_{2} \mathrm{O}_{3}=0.9$ and $\mathrm{H}_{2} \mathrm{O} / \mathrm{Na}_{2} \mathrm{O}=14.5$ (calculations made by considering only the reactive silica of the metakaolin, around $26 \%$ ).

Then, the pastes were cast in $9.1 \times 6.2 \times 4 \mathrm{~cm}$ (large) or $7 \times 4.3 \times 2.2 \mathrm{~cm}$ (small) plastic prisms, hermetically sealed, and stored at $20^{\circ} \mathrm{C}$. After $24 \mathrm{~h}$, the large prisms were divided into three: one part remained hermetically sealed at $20^{\circ} \mathrm{C}$, another part was removed from the mould and placed in moist conditions $\left(95 \% \mathrm{RH}, 20^{\circ} \mathrm{C}\right.$, atmospheric $\left.\mathrm{CO}_{2} \%\right)$, and the last part was placed in a controlled carbonation chamber at $50 \%$ R.H., $20^{\circ} \mathrm{C}$ and $50 \% \mathrm{CO}_{2}$. At various times (1, 3, 5, 7 and 14 days) some prisms were crushed and placed in a high-pressure device for extracting fluid from porous materials [6] in order to obtain the geopolymer pore solution. The solution was analysed immediately after the extraction to avoid further carbonation, by measuring the $\mathrm{pH}$ using a $\mathrm{pH}$ metric titration by $\mathrm{HCl}(0.5 \mathrm{M})$, and by Fourier transform infrared spectroscopy (FTIR, PerkinElmer Spectrum). All the small prisms were demoulded after $24 \mathrm{~h}$ and cured in one of three different conditions: natural conditions $\left(20^{\circ} \mathrm{C}, 95 \%\right.$ R.H. and atmospheric $\left.\mathrm{CO}_{2} \%\right)$ and accelerated conditions at $20^{\circ} \mathrm{C}, 50 \%$ R.H., and 4 or $50 \%$ of $\mathrm{CO}_{2}$. After 7 days, all prisms were semi-immersed in demineralized water to generate efflorescence. Once there were enough crystals, the efflorescence was analysed by FTIR.

\section{Results and discussion}

\section{pH of the pore solution}

Figure 1 reports the evolution of the $\mathrm{pH}$ inside the geopolymer pores up to 180 days, for samples kept at $20^{\circ} \mathrm{C}$ and $95 \%$ R.H., i.e. in contact with the atmosphere, and the sample which had no exchange with the atmosphere. It can be seen that, although there was a strong initial $\mathrm{pH}$ of 14 , which was imposed by the activating solution, the $\mathrm{pH}$ dropped rapidly in the following days, at a rate proportional to the logarithm of time. After 14 days, the $\mathrm{pH}$ of the pore solution of geopolymers exposed to atmospheric $\mathrm{CO}_{2}$ was lower than 12 and reached 10.5 at 6 months, while it was still greater than 12 for the samples kept in conditions without external exchange.

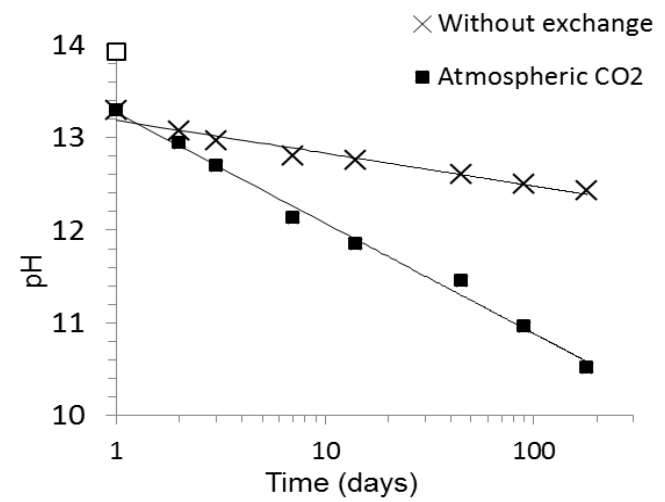

Figure 1: pH evolution of the geopolymer pore solution for pastes cured at: (a) $95 \%$ R.H. and atmospheric $\mathrm{CO}_{2} \%$; and $(x)$ at $20^{\circ} \mathrm{C}$ in hermetically sealed plastic prisms. 
This difference in the $\mathrm{pH}$ evolution was due to the carbonation of the pore solution in the geopolymers exposed to atmospheric $\mathrm{CO}_{2}$, which led to the consumption of hydroxide to form $\mathrm{CO}_{3}{ }^{2-}$ ions and sodium carbonates, according to the following reactions: $2 \mathrm{HO}^{-}+\mathrm{CO}_{2} \rightarrow \mathrm{CO}_{3}{ }^{2-}+$ $\mathrm{H}_{2} \mathrm{O}$ and $2 \mathrm{Na}^{+}+\mathrm{CO}_{3}{ }^{2-} \rightarrow \mathrm{Na}_{2} \mathrm{CO}_{3}$.

\section{Infrared analysis}

Figure 2a) shows the infrared spectrum between the wavenumbers of 800 and $2000 \mathrm{~cm}^{-1}$ for the pore solutions extracted after 1, 3, 5, 7 and 14 days from the geopolymer paste kept at $20^{\circ} \mathrm{C}, 95 \%$ R.H., at atmospheric $\mathrm{CO}_{2} \%$. In order to identify and quantify the sodium carbonate formed in these pore solutions, measurements were also made in the infrared with five pure $\mathrm{Na}_{2} \mathrm{CO}_{3}$ solutions having mass concentrations of 10, 50, 100, 150, and 200 g.L ${ }^{-1}$ (Figure 2b).
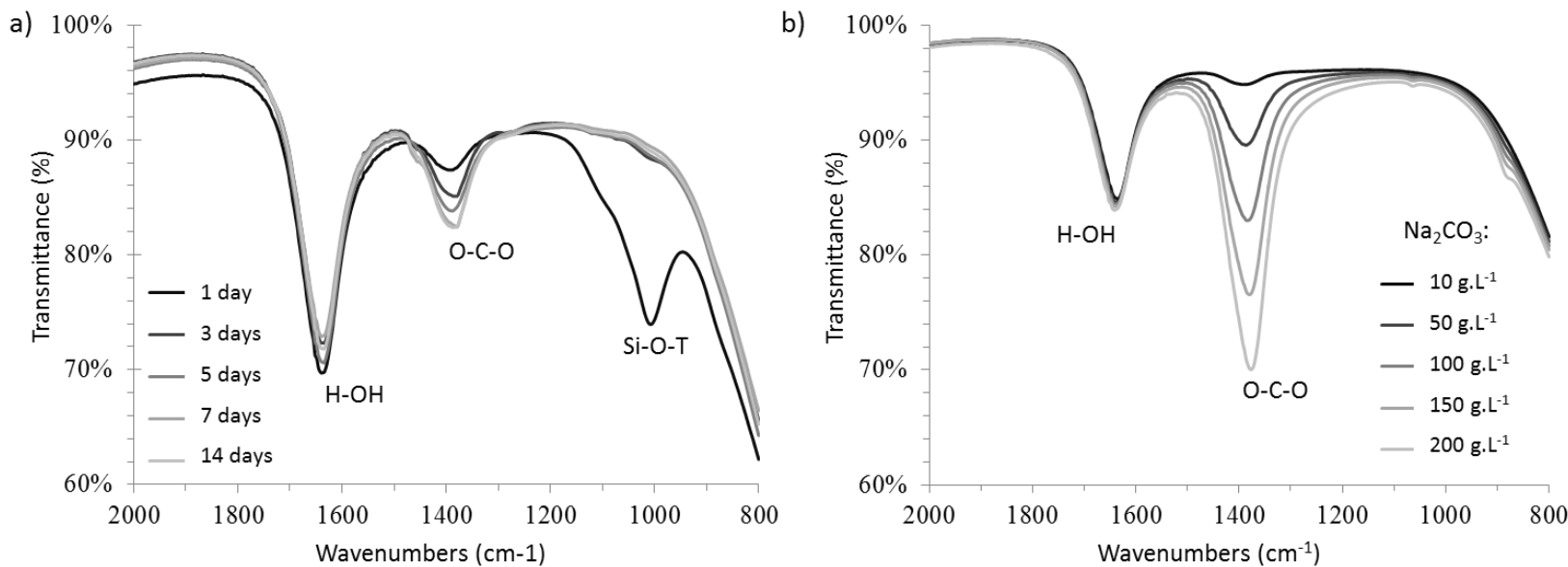

Figure 2: Infrared spectra of a) pore solutions of geopolymer paste cured at $20^{\circ} \mathrm{C}, 95 \%$ R.H. and atmospheric $\mathrm{CO}_{2} \%$, extracted after 1, 3, 5, 7 and 14 days and b) pure $\mathrm{Na}_{2} \mathrm{CO}_{3}$ solutions having the following mass concentrations: 10, 50, 100, 150, and 200 g.L. $\mathrm{L}^{-1}$.

All spectrums exhibited infrared vibration modes between $1640 \mathrm{~cm}^{-1}$ and $1635 \mathrm{~cm}^{-1}$, associated with bending vibrations of $\mathrm{H}-\mathrm{OH}$ bonds and related to water [2]. A mode was also clearly identified in both cases between 1382 and $1394 \mathrm{~cm}^{-1}$, associated with the stretching vibration of $\mathrm{O}-\mathrm{C}-\mathrm{O}$ bonds in the carbonate group $\left(\mathrm{CO}_{3}{ }^{2-}\right)$ [2]. This association was confirmed by the increase of the intensity of the vibration at these wavenumbers when the mass concentrations of carbonate solutions increased (Figure $2 \mathrm{~b}$ ) or with the augmentation of curing time at atmospheric $\mathrm{CO}_{2} \%$ (Figure 2a). The mode at $1008 \mathrm{~cm}^{-1}$, only in the spectrum of the extracted pore solution at 1 day, was assigned to the asymmetric stretching vibration of $\mathrm{Si}-\mathrm{O}-\mathrm{T}$ bonds, where $\mathrm{T}$ is tetrahedral silicon or aluminium [2,3]. The presence of this mode only in the pore solution extracted after $24 \mathrm{~h}$ demonstrated the presence of solid particles in suspension, probably due to the fact that the geopolymerization was not completed at that time.

The calibration curve shown in Figure 3 was drawn up by integrating the areas under the peaks associated with the carbonate vibrations (between 1510 and $1094 \mathrm{~cm}^{-1}$ ) and plotting them versus the mass concentration of the references. Integrating the $\mathrm{CO}_{3}{ }^{2-}$ vibration mode of the infrared spectrums of the geopolymer pore solutions allowed the mass concentration of sodium carbonate to be calculated over time with the calibration curve (Table 1). These results show very fast carbonation as the mass concentration increased from $16.1 \mathrm{~g} . \mathrm{L}^{-1}$ at $24 \mathrm{~h}$ to $30.7 \mathrm{~g} . \mathrm{L}^{-1}$ at only 3 days, followed by a rather slow evolution reaching the value of $39.8 \mathrm{~g} . \mathrm{L}^{-1}$ for 7 days and longer. 


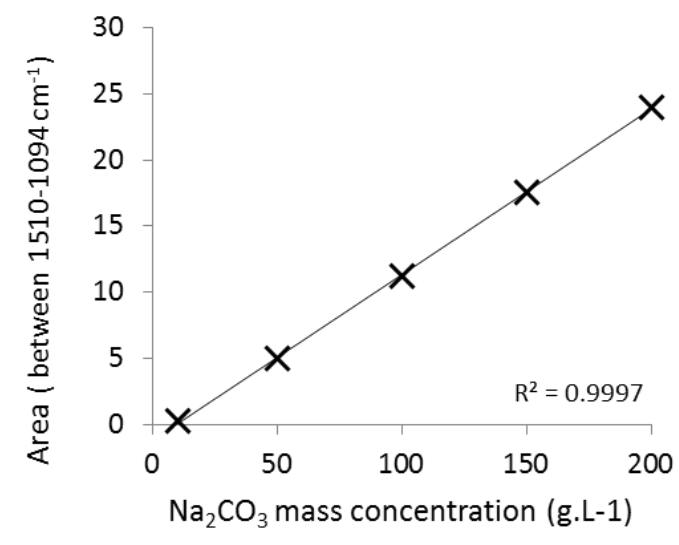

Table 1: Mass concentration of $\mathrm{Na}_{2} \mathrm{CO}_{3}\left(\mathrm{~g} . \mathrm{L}^{-1}\right)$ in the geopolymer pore solutions at 3, 5, 7 and 14 days (calculated from the calibration curve).

\begin{tabular}{ccccc}
\hline Time & 3 days & 5 days & 7 days & 14 days \\
\hline $\begin{array}{l}\mathrm{Na}_{2} \mathrm{CO}_{3} \text { mass } \\
\text { concentration }\end{array}$ & $30.7 \mathrm{~g} . \mathrm{L}^{-1}$ & $31.9 \mathrm{~g} . \mathrm{L}^{-1}$ & $39.8 \mathrm{~g} . \mathrm{L}^{-1}$ & $39.8 \mathrm{~g} . \mathrm{L}^{-1}$ \\
\hline
\end{tabular}

Figure 3 (On the left): Calibration curve of the area of the carbonate vibrations $\left(10,50,100,150\right.$, and $\left.200 \mathrm{~g} . \mathrm{L}^{-1}\right)$ between 1510 and $1094 \mathrm{~cm}^{-1}$, plotted versus the mass concentration of the references.

\section{Titration by HCl}

A titration with HCL at $0.5 \mathrm{M}$ was performed on the pore solutions of the geopolymer extracted after 3 days of curing $\left(20^{\circ} \mathrm{C}, 95 \%\right.$ R.H. and natural $\left.\mathrm{CO}_{2}\right)$. The evolution of the $\mathrm{pH}$ is shown in Figure 4. This curve shows three falls of the $\mathrm{pH}$ value and highlights the three successive reactions that took place in the solution during the titration. First, the $\mathrm{H}_{3} \mathrm{O}^{+}$provided by $\mathrm{HCl}$ reacted with the $\mathrm{OH}^{-}$of the solution. A volume $\mathrm{V}_{1}=1.15 \mathrm{~mL}$ of $\mathrm{HCl}$ was necessary to consume all the $\mathrm{OH}^{-}$, leading to a first drop of $\mathrm{pH}$. This first step demonstrated that the solution was not completely carbonated. The second drop showed the amount of acid $\left(\mathrm{V}_{2}=2.35 \mathrm{~mL}\right)$ necessary to transform all the $\mathrm{CO}_{3}{ }^{2-}$ into $\mathrm{HCO}_{3}{ }^{-}$. This volume and the $\mathrm{HCl}$ concentration being known, the carbonate concentration could be calculated (results in Table 2). The third drop marked the end of the reaction between the $\mathrm{H}_{3} \mathrm{O}^{+}$and the $\mathrm{HCO}_{3}{ }^{-}$formed previously $\left(\mathrm{V}_{3}=2.35 \mathrm{~mL}\right)$. The fact that the volumes $\mathrm{V}_{2}$ and $\mathrm{V}_{3}$ were identical means that no $\mathrm{HCO}_{3}{ }^{-}$was initially present in the pore solution (since all $\mathrm{HCO}_{3}{ }^{-}$came from the second reaction during the titration). These titrations carried out on the pore solution at $3,5,7$ and 14 days determined the sodium carbonate concentration and the degree of carbonation presented in Table 2. The carbonate concentrations obtained are in agreement with the infrared results presented previously (although slightly lower), and calculation of the degree of carbonation showed that the pore solution was $97 \%$ carbonated in just 7 days.

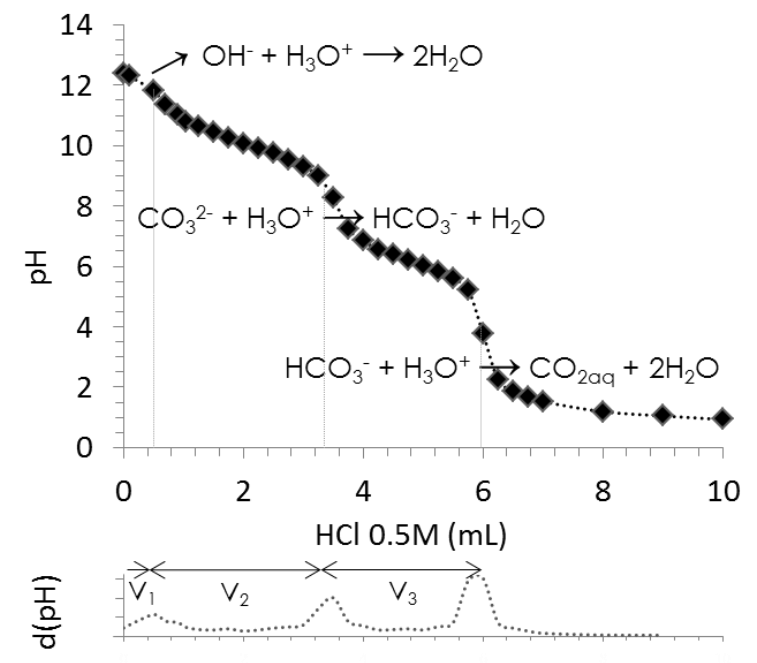

Table 2: Mass concentration of $\mathrm{Na}_{2} \mathrm{CO}_{3}\left(\mathrm{~g} . \mathrm{L}^{-1}\right)$ and degree of carbonation (\%) of the geopolymer pore solutions at 3,5,7 and 14 days.

\begin{tabular}{ccccc}
\hline Time & 3 days & 5 days & 7 days & 14 days \\
\hline $\begin{array}{c}\mathrm{Na}_{2} \mathrm{CO}_{3} \text { mass } \\
\text { concentration }\end{array}$ & $24.9 \mathrm{~g} \cdot \mathrm{L}^{-1}$ & $28.6 \mathrm{~g} \cdot \mathrm{L}^{-1}$ & $37.1 \mathrm{~g} \cdot \mathrm{L}^{-1}$ & $37.1 \mathrm{~g} \cdot \mathrm{L}^{-1}$ \\
\hline $\begin{array}{c}\text { Degree of } \\
\text { carbonation }\end{array}$ & $80 \%$ & $89 \%$ & $97 \%$ & $97 \%$ \\
\hline
\end{tabular}

Figure 4 (On the left): Titration curve of geopolymer pore solution extracted after 3 days of curing $\left(20^{\circ} \mathrm{C}, 95 \%\right.$ R.H. and natural $\mathrm{CO}_{2}$ ) by a $0.5 \mathrm{M} \mathrm{HCl}$ solution followed by $\mathrm{pH}$, and the derivative of the $\mathrm{pH}$ (below)

The same measurements were performed on pore solutions extracted from geopolymer cured at $20{ }^{\circ} \mathrm{C}, 50 \%$ R.H. and $50 \%$ of $\mathrm{CO}_{2}$. On the titration curve of the solution extracted at 3 days (Figure 5), the drop of $\mathrm{pH}$ corresponding to the $\mathrm{OH}^{-}$was no longer visible and the volume required to react the $\mathrm{CO}_{3}{ }^{2-}\left(\mathrm{V}_{1}=9.5 \mathrm{~mL}\right)$ was less than the volume required for the $\mathrm{HCO}_{3}{ }^{-}\left(\mathrm{V}_{2}=12 \mathrm{~mL}\right)$. Based on these results, it can be stated that the solution was already fully carbonated at 3 days and also that, 
unlike previous solutions analysed, the extracted pore solution contained $\mathrm{HCO}_{3}{ }^{-}$. The presence of bicarbonate in solution has a great influence on the $\mathrm{pH}$ : as can be seen in Figure 6, the $\mathrm{pH}$ value decreases when the proportion of bicarbonate in a carbonate/bicarbonate mixture increases. This explains the low $\mathrm{pH}$ of the solution, 10.5 instead of the 12.5 measured at the same age for the pore solution of geopolymer kept in natural $\mathrm{CO}_{2}$ conditions. Titrations performed at various times allowed the bicarbonate rate to be followed over time (Table 3 ) and the $\mathrm{pH}$ value to be anticipated using a theoretical $\mathrm{pH}$ curve made with pure carbonate and bicarbonate (Figure 6). This study shows that the use of accelerated tests to study the carbonation of geopolymer is not realistic because they not only increase the kinetics of the natural reaction but also lead to different reaction products. Such tests thus result in false conclusions, that is to say a $\mathrm{pH}$ low enough to cause the depassivation of steel reinforcements when, in fact, the $\mathrm{pH}$ should remain at a higher value in natural conditions.

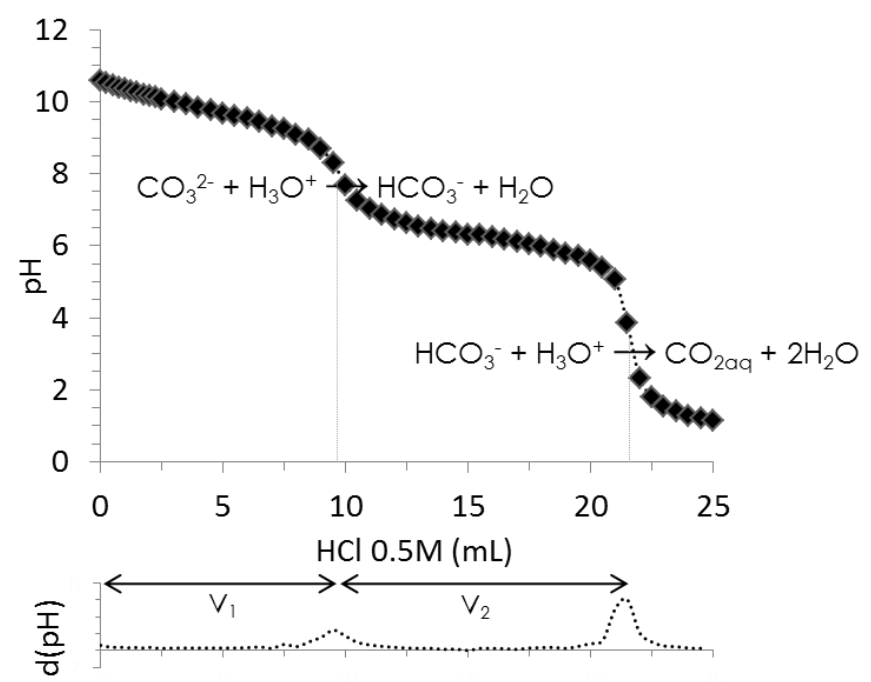

Figure 5: Titration curve of geopolymer pore solution extracted after 3 days of curing $\left(20^{\circ} \mathrm{C}, 50 \%\right.$ R.H. and $50 \%$ of $\left.\mathrm{CO}_{2}\right)$ by a $0.5 \mathrm{M} \mathrm{HCl}$ solution followed by $\mathrm{pH}$, and the derivative of the $\mathrm{pH}$ (bottom curve).
Table 3: Percentage of $\mathrm{NaHCO} 3$ in the geopolymer pore solutions $\left(20^{\circ} \mathrm{C}, 50 \%\right.$ R.H. and $50 \%$ of $\left.\mathrm{CO}_{2}\right)$ at $3,5,7$ and 14 days.

\begin{tabular}{ccccc}
\hline Time & 3 days & 5 days & 7 days & 14 days \\
\hline $\begin{array}{c}\mathrm{NaHCO}_{3} \\
\text { rate }\end{array}$ & $21 \%$ & $30 \%$ & $31 \%$ & $38 \%$ \\
\hline
\end{tabular}

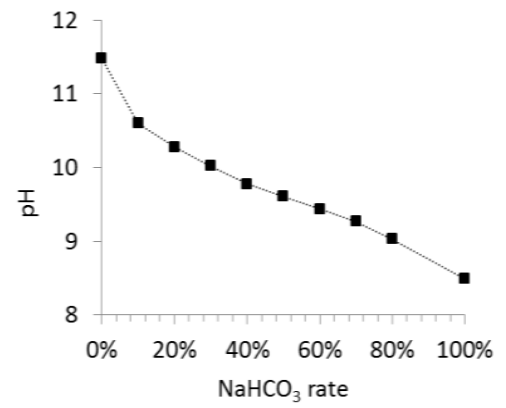

Figure 6: $\mathrm{pH}$ of carbonate/bicarbonate mixture $\left(100 \mathrm{~g} . \mathrm{L}^{-1}\right)$ prepared from pure product depending on the bicarbonate content.

\section{Efflorescence tests}

The $\mathrm{pH}$ of the pore solution of geopolymer kept in natural conditions is thus not prejudicial. However, the risk of efflorescence related to the very high alkali content needs to be assessed. As it was shown that seven days was sufficient to almost completely carbonate the pore solution, all the small prisms were left in an atmosphere with $4 \%$ (natural air) or $50 \% \mathrm{CO}_{2}$ and $50 \%$ R.H., for one week and then placed in semi-immersion to cause the growth of carbonate crystals. After 7 days of semi-immersion, all prisms presented white crystals on their surfaces, in approximately equivalent amounts for all curing conditions. The crystals were recovered and analysed by FTIR for the atmospheres with a natural level (Figure 7a) and $50 \%$ of $\mathrm{CO}_{2}$ (Figure 7b), and compared to pure sodium carbonate and bicarbonate. Again, this study showed differences in the carbonation reaction products of geopolymer between natural and accelerated tests. 

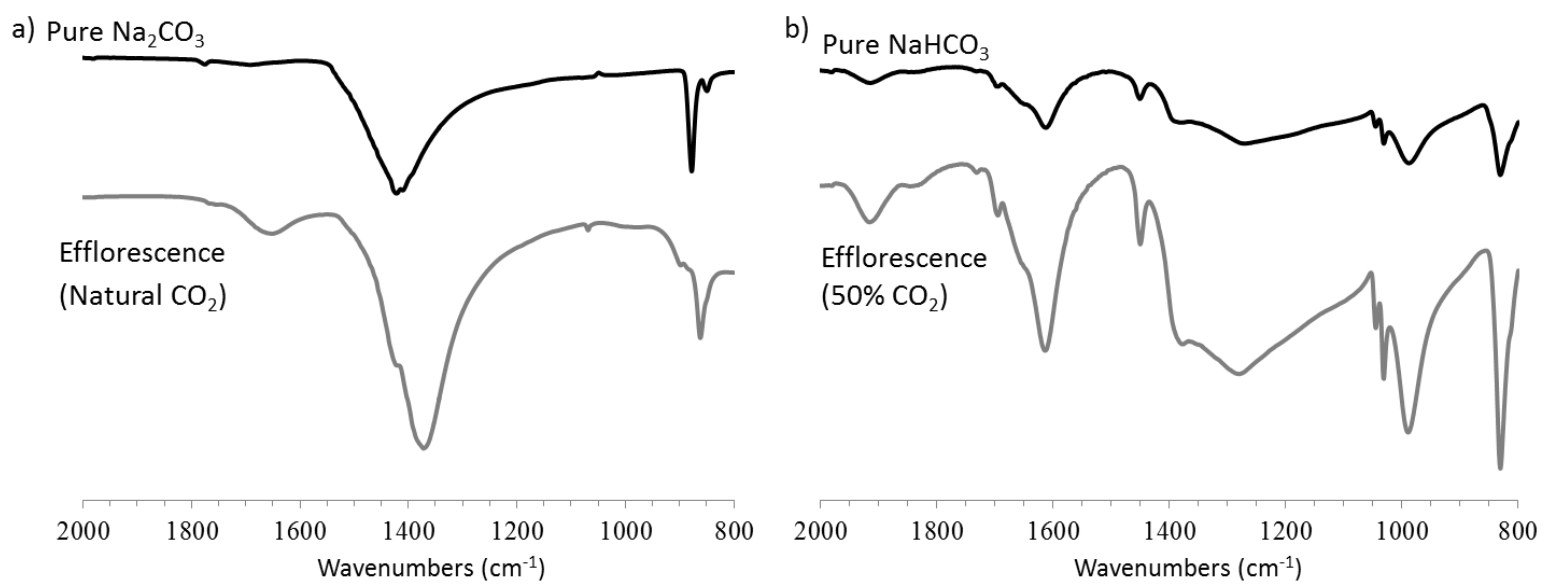

Figure 7: Infrared spectra of a) pure $\mathrm{Na}_{2} \mathrm{CO}_{3}$ and efflorescence residues of geopolymer cured at natural $\mathrm{CO}_{2} \%$ b) pure $\mathrm{NaHCO}_{3}$ and efflorescence residue of geopolymer cured at $50 \%$ of $\mathrm{CO}_{2}$.

\section{Conclusion}

The experimental studies performed in this study were intended to assess the natural and accelerated carbonation of metakaolin-based geopolymer activated by sodium silicate. The work was carried out on geopolymer pore solutions using FTIR and $\mathrm{pH}$-meter titration and efflorescence tests were performed on geopolymer pastes. From the experimental results obtained in this study, the following conclusions can be drawn:

- After 180 days, the $\mathrm{pH}$ of the pore solution of geopolymer pastes cured in natural conditions presented no risk of corrosion by carbonation, since the $\mathrm{pH}$ value of the pore solution was higher than the steel depassivation limit.

- The geopolymer was carbonated at $97 \%$ after 7 days of exposure to atmospheric levels of $\mathrm{CO}_{2}$.

- Exposure to high $\mathrm{CO}_{2}$ contents (e.g. 50\%) leads to the formation of sodium bicarbonate, resulting in a lower $\mathrm{pH}$ of the pore solution.

- The risk of efflorescence on the surface of geopolymer is significant and needs to be assessed in the aim of finding a way to prevent it.

Due to their very high alkali content compared to OPC, geopolymers are open to many questions, especially regarding their durability. The results of this study provide some answers concerning carbonation, showing that it would not be detrimental to steel reinforcement but that the risks of efflorescence are significant and need to be evaluated in order to be prevented.

\section{References}

[1] T. Bakharev, J. Sanjayan, Y. B. Cheng, Resistance of alkali-activated slag concrete to carbonation, Cem Concr Res, 31(2001) 1277-1283.

[2] S. A. Bernal, R. M. de Gutierrez, J. L. Provis, V. Rose, Effect of silicate modulus and metakaolin incorporation on the carbonation of alkali silicate-activated slags, Cem Concr Res, 40(2010) 898-907.

[3] M. Criado, A. Palomo, A. Fernández-Jiménez, Alkali activation of fly ashes. Part 1: Effect of curing conditions on the carbonation of the reaction products, Fuel, 84(2005) 2048-2054.

[4] S. A. Bernal, J. L. Provis, D. G. Brice, A. Kilcullen, P. Duxson, J. S. J van Deventer, Accelerated carbonation testing of alkali-activated binders significantly underestimates service life: The role of pore solution chemistry, Cem Concr Res, 42(2012) 1317-1326.

[5] R. San Nicolas, M. Cyr, G. Escadeillas, (2013) Characteristics and applications of flash metakaolins, Appl Clay Sci 83-84(2013) 253-262.

[6] M. Cyr, P. Rivard, F. Labrecque, A. Daidié, High-pressure device for fluid extraction from porous materials: application to cement-based materials, J Am Ceram Soc 91(2008) 2653-2658. 